Heidi Möller

Menschen, die getötet haben 
Heidi Möller

\section{Menschen, \\ die getötet haben}

Tiefenbermeneutische Analysen von Tötungsdelinquenten 
Die Deutsche Bibliothek - CIP-Einheitsaufnahme

\section{Möller, Heidi:}

Menschen, die getötet haben: tiefenhermeneutische Analysen von Tötungsdelinquenten / Heidi Möller. Opladen: Westdt. Verl., 1996

ISBN 978-3-531-12821-4 ISBN 978-3-322-90634-2 (eBook)

DOI 10.1007/978-3-322-90634-2

Alle Rechte vorbehalten

(C) 1996 Westdeutscher Verlag GmbH, Opladen

Der Westdeutsche Verlag ist ein Unternehmen der Bertelsmann Fachinformation.

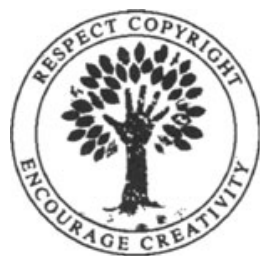

Das Werk einschließlich aller seiner Teile ist urheberrechtlich geschützt. Jede Verwertung außerhalb der engen Grenzen des Urheberrechtsgesetzes ist ohne Zustimmung des Verlags unzulässig und strafbar. Das gilt insbesondere für Vervielfältigungen, Übersetzungen, Mikroverfilmungen und die Einspeicherung und Verarbeitung in elektronischen Systemen.

Umschlaggestaltung: Horst Dieter Bürkle, Darmstadt

Gedruckt auf säurefreiem Papier 


\section{Das Ende des Wortes Nie}

Nie könnte ich lügen, wie oft habe ich es schon getan. Nie könnte ich ungehorsam sein, wie oft bin ich es schon gewesen.

Nie könnte ich meiner Frau untreu sein, und doch geschah auch dies einmal. Nie könnte ich einen Menschen schlagen, doch einmal bin ich ausgerastet.

Nie könnte ich einen Menschen töten, so dachte ich

bis zu dem Tag, an dem meine Frau starb, durch meine Hände.

Das war das Ende des Wortes NIE. 


\section{Inhalt}

Einleitung

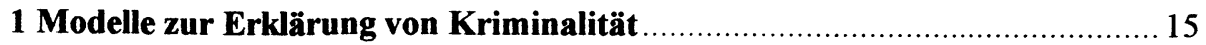

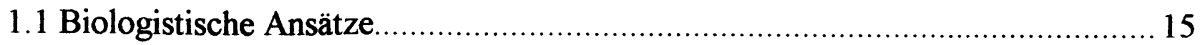

1.2 Das Konzept der Psychopathischen Persönlichkeit ......................................... 17

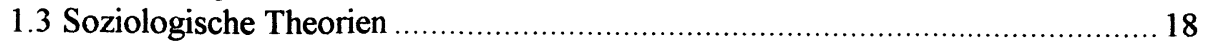

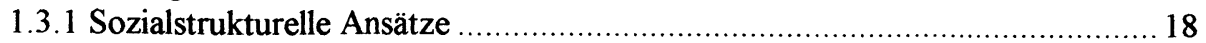

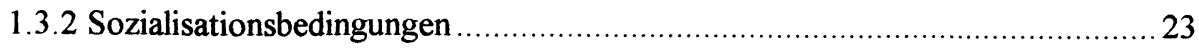

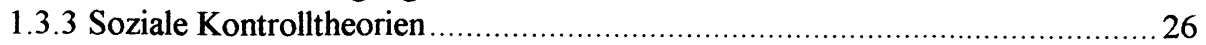

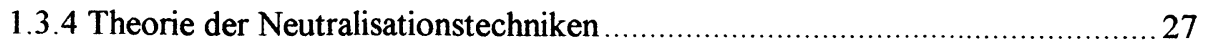

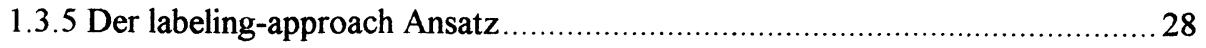

1.4 Psychodynamische Theorien älterer Provenienz ………..............................2. 29

1.4.1 Freud: Der Verbrecher aus Schuldbewußtsein ..........................................229

1.4.2 Alexander und Staub: Der Verbrecher und seine Richter..............................30

1.4.3 Stekels Konzept des universell kriminellen Kindes ...................................... 31

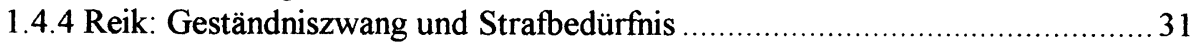

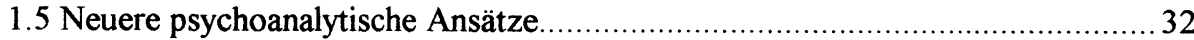

1.5.1 Moser: Jugendkriminalität und Gesellschaftsstruktur.................................... 32

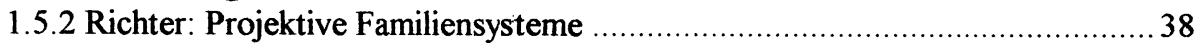

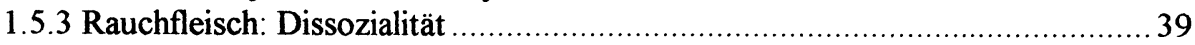

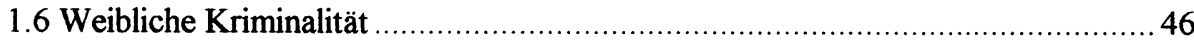

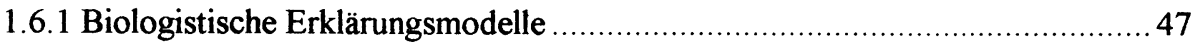

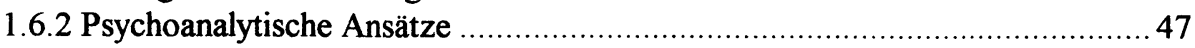

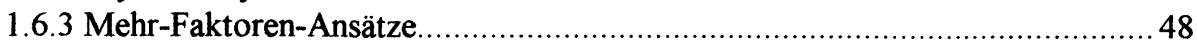

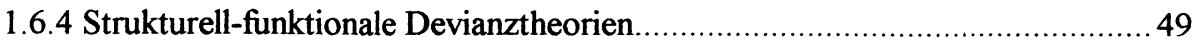

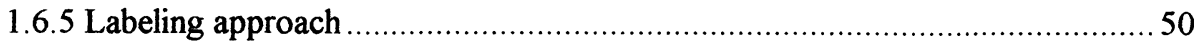

1.6.6 „Männliche“ Kriminalität und „weibliche“ Krankheit? ...................................51

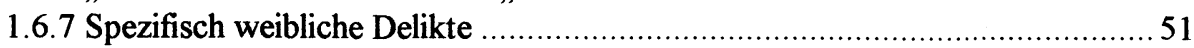

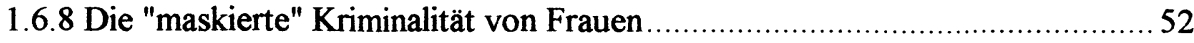

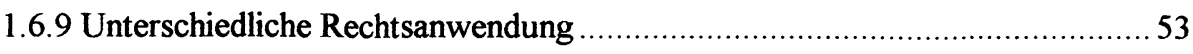

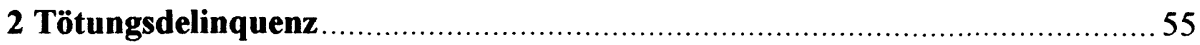

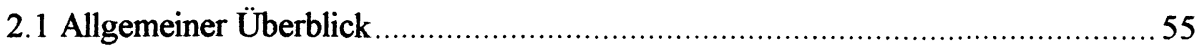

2.2 Klassifikationsmöglichkeiten von Tötungsdelikten ........................................5

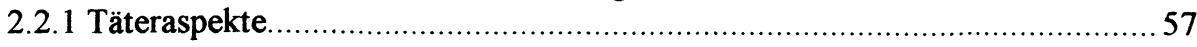

2.2.2 Situationsaspekte 


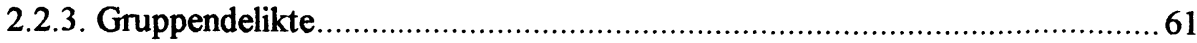

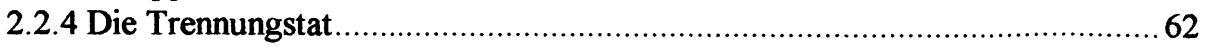

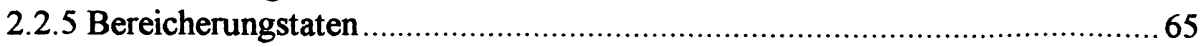

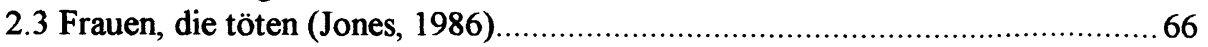

2.3.1 Geschlechtsspezifische Aspekte der Tötungskriminalität ................................67

2.3.2 Geschlechtsspezifische Diskriminierung von Frauen, die töten .......................69

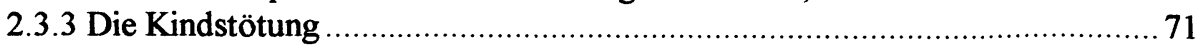

2.3.4 Soziologische Daten über Frauen, die töten .............................................. 72

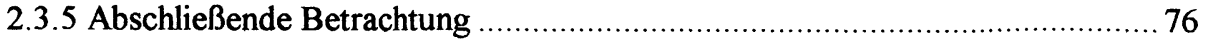

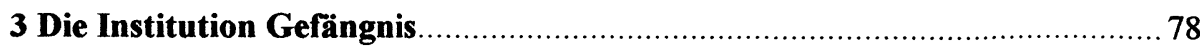

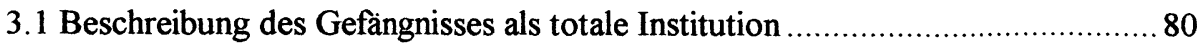

3.2 Die gesellschaftliche Funktion der Justizvollzugsanstalten................................ 81

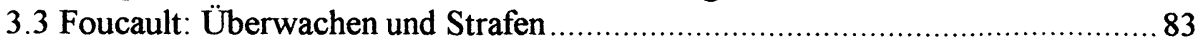

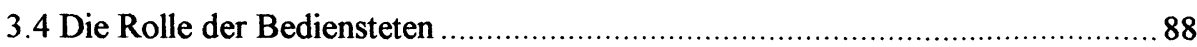

3.5 Die Funktion der Organisation Gefängnis für die Bediensteten .........................99

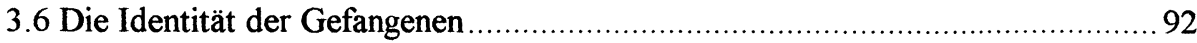

3.7 Die Rolle der totalen Institution für die Gefangenen....................................92

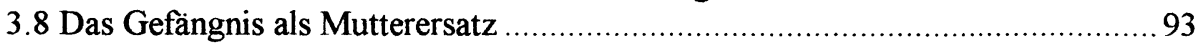

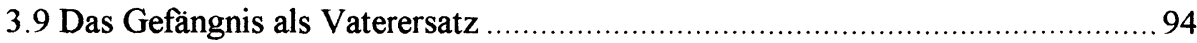

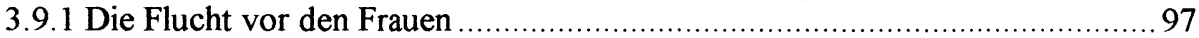

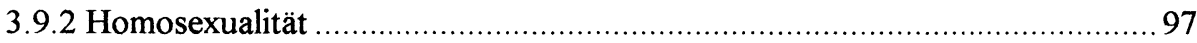

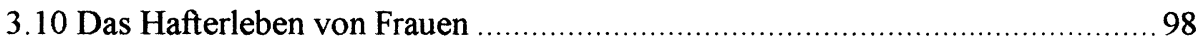

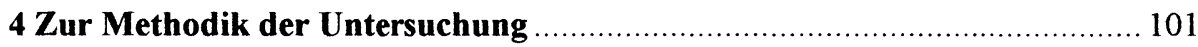

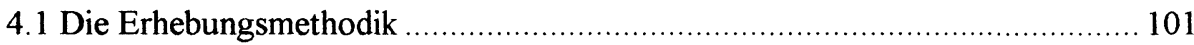

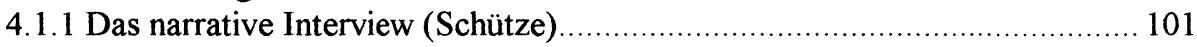

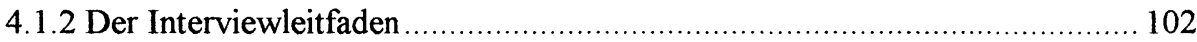

4.2 Grundsätzliches zur Erhebung von Biographien der Straftäter....................... 103

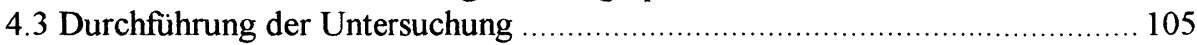

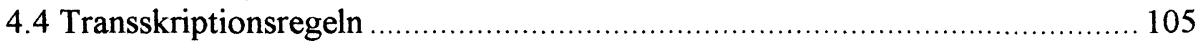

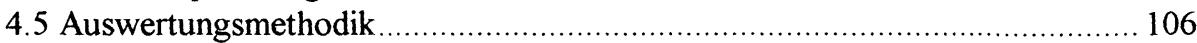

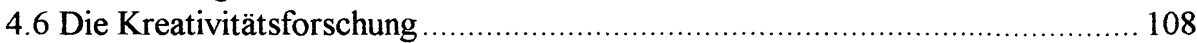

4.6.1 Das Modell des kreativen Prozesses ....................................................... 108

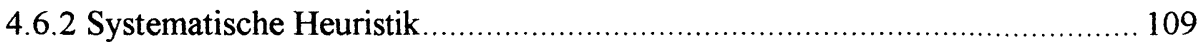

4.7 Kommunikative Validierung durch Korrespondenzprozesse ........................... 110

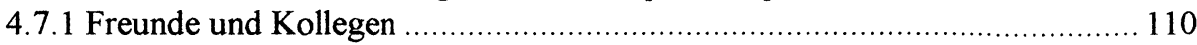

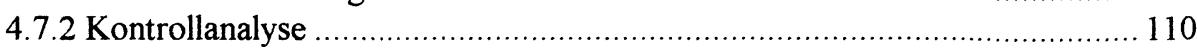

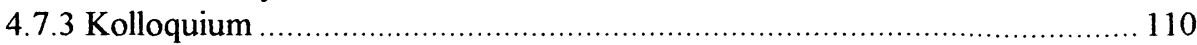

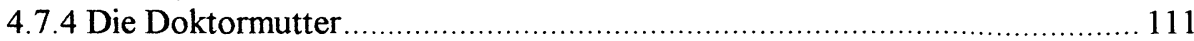

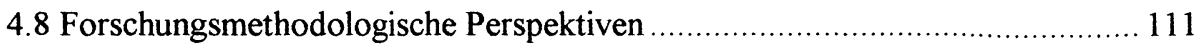

4.8.1 Tiefenhermeneutische Analyse nach Leithäuser \& Volmerg ........................ 111 
4.8.2 Die Methode des Auswertens nach Leithäuser \& Volmerg........................... 112

4.8.3 Tiefenhermeneutische Interpretation von Texten ....................................... 113

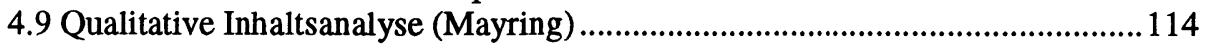

4.10 Psychotherapeutische/diagnostische Perspektiven .......................................116

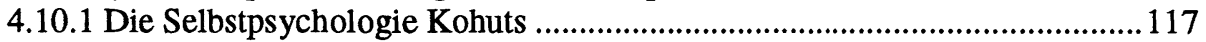

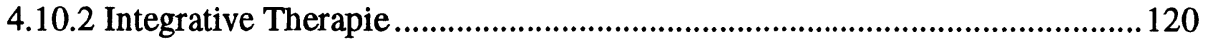

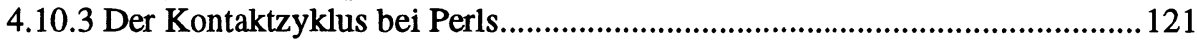

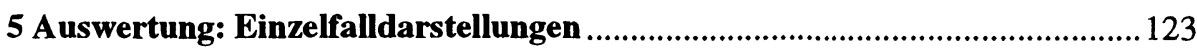

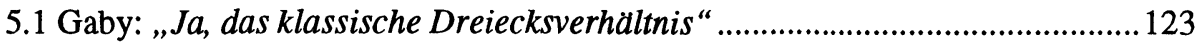

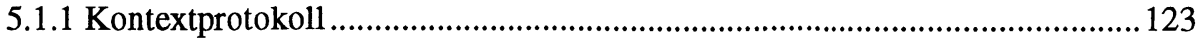

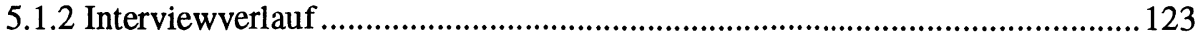

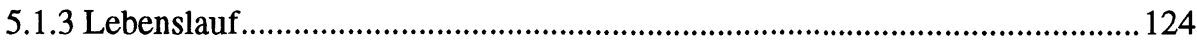

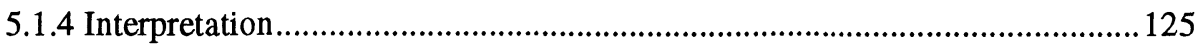

5.2 Gertrud: „Der Zeitpunkt war da, fur mich was zu tun “...................................133

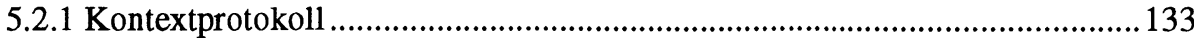

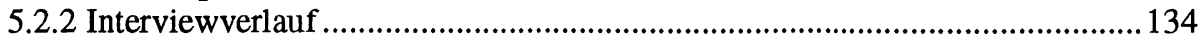

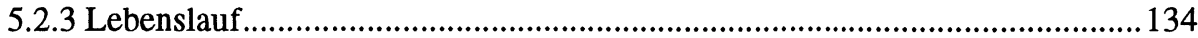

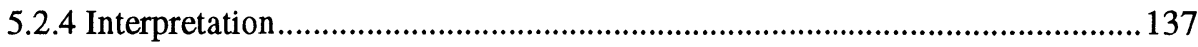

5.3 Monalisa: ,Weil ich meine Knastzeit so liebe und eine der Lebens-

langlichen bin, die so schwer zu entlassen sind "............................149

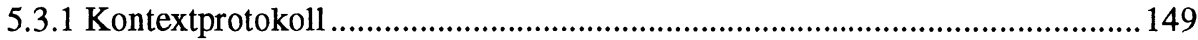

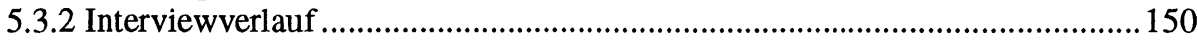

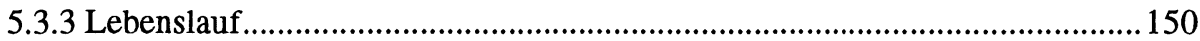

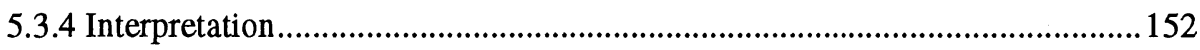

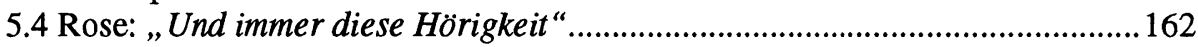

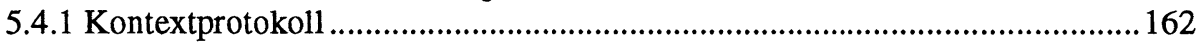

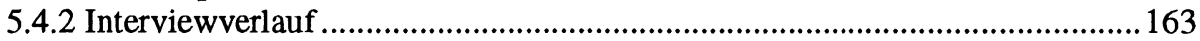

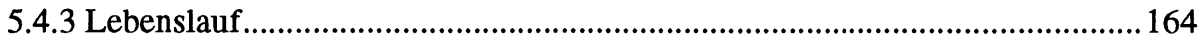

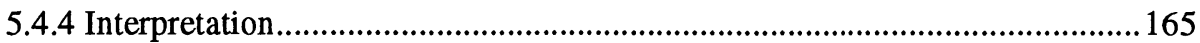

5.5 Erika: "Ich bin keen Mensch, ich bin 'n Ungeheuer..." .................................. 180

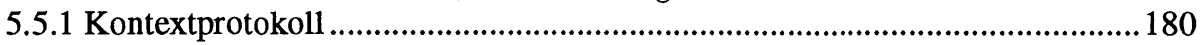

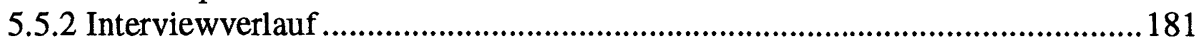

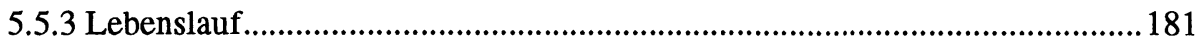

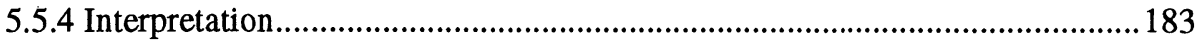

5.6 Hans: „Ich hab keine Abwehrstoffe gehabt dagegen“ "......................................197

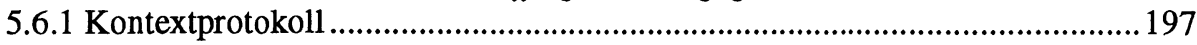

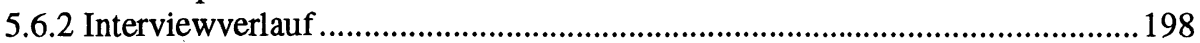

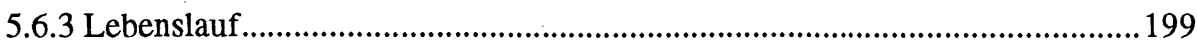

5.6.4 Interpretation...............................................................................................2. 202

5.7 Heinz: „Formell war ja alles lieb und nett; formell war alles mit dem lieben Gott ausgehandelt und bestens geregelt. "..........................213

5.7.1 Kontextprotokoll ...................................................................................213

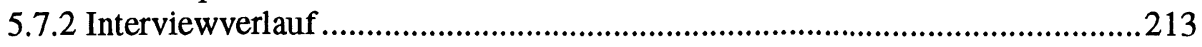


5.7.3 Lebenslauf

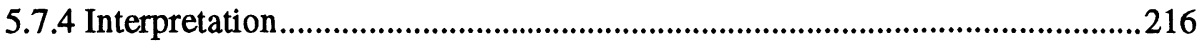

5.8 Pierre: „Ick bin nu ma en Mörder “................................................................230

5.8.1 Kontextprotokoll .....................................................................................230

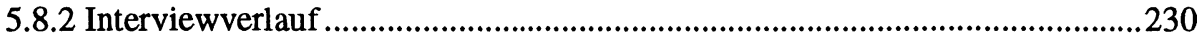

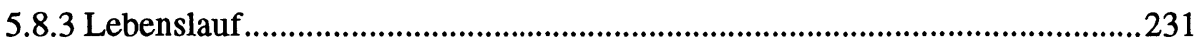

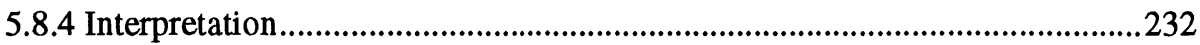

5.9 Rolf: „Ich lebe, weil ich nicht sterben will. Das ist alles “..................................244

5.9.1 Kontextprotokoll ...............................................................................................244

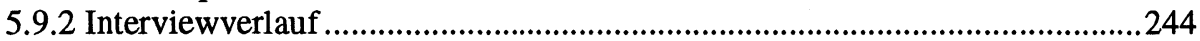

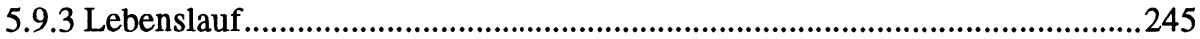

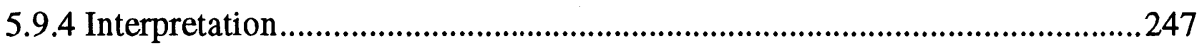

5.10 Stefan: „Und grade die, die so groß und laut tönen, es unmöglich finden, daß die fur mich eigentlich am gefahrdetsten sind “..............260

5.10 .1 Kontextprotokoll .........................................................................................260

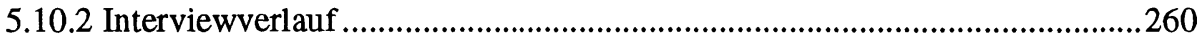

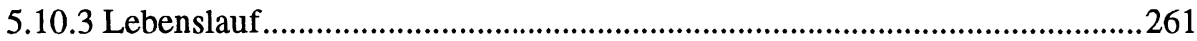

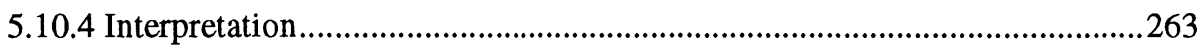

6 Schlußfolgerungen: Das Gefängnis als "Stützkorsett" des Ichs ....................273

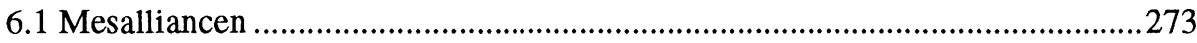

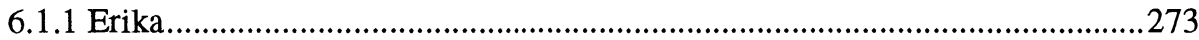

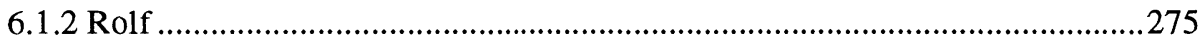

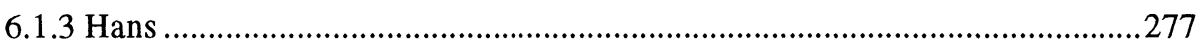

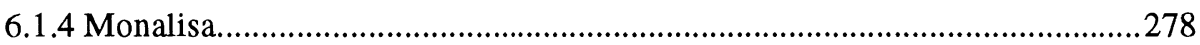

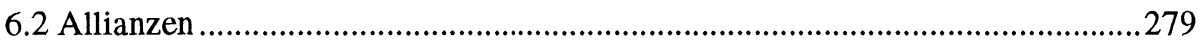

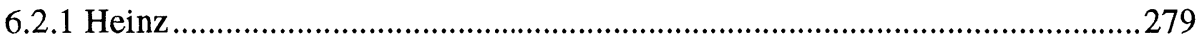

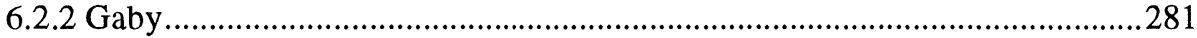

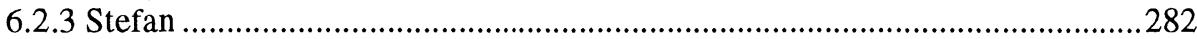

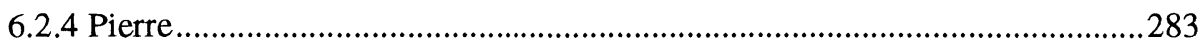

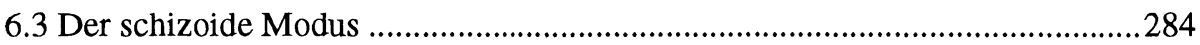

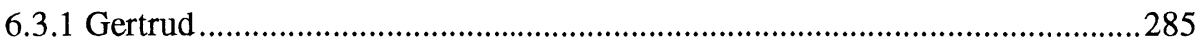

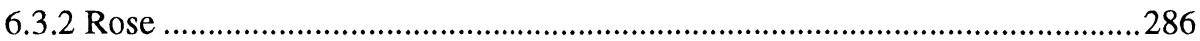

7 Anmerkungen zur Psychotherapie mit Dissozialen ......................................28

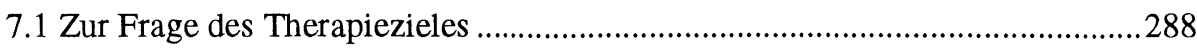

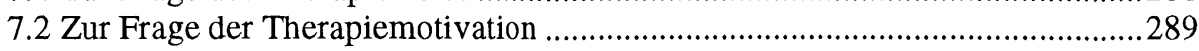

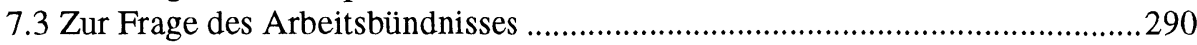

7.4 Zur Frage der Gegenübertragungsphänomene ..............................................290

7.5 Zur Frage erlebnisaktivierender Methoden .....................................................291

7.6 Zur Frage der Spezifität der Psychotherapie weiblicher Therapeuten mit Straffälligen 
8 Ausblick

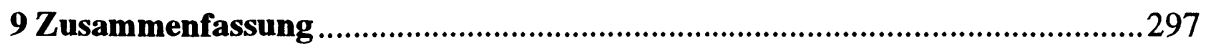

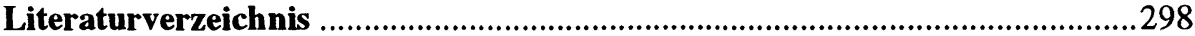

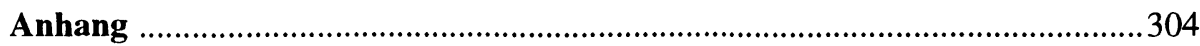

